Document downloaded from:

http://hdl.handle.net/10251/64427

This paper must be cited as:

Ruiz Martinez, A.; Serralta Sevilla, J.; Seco Torrecillas, A.; Ferrer, J. (2015). Effect of temperature on ammonium removal in Scenedesmus sp. Bioresource Technology. 191:346349. doi:10.1016/j.biortech.2015.05.070.

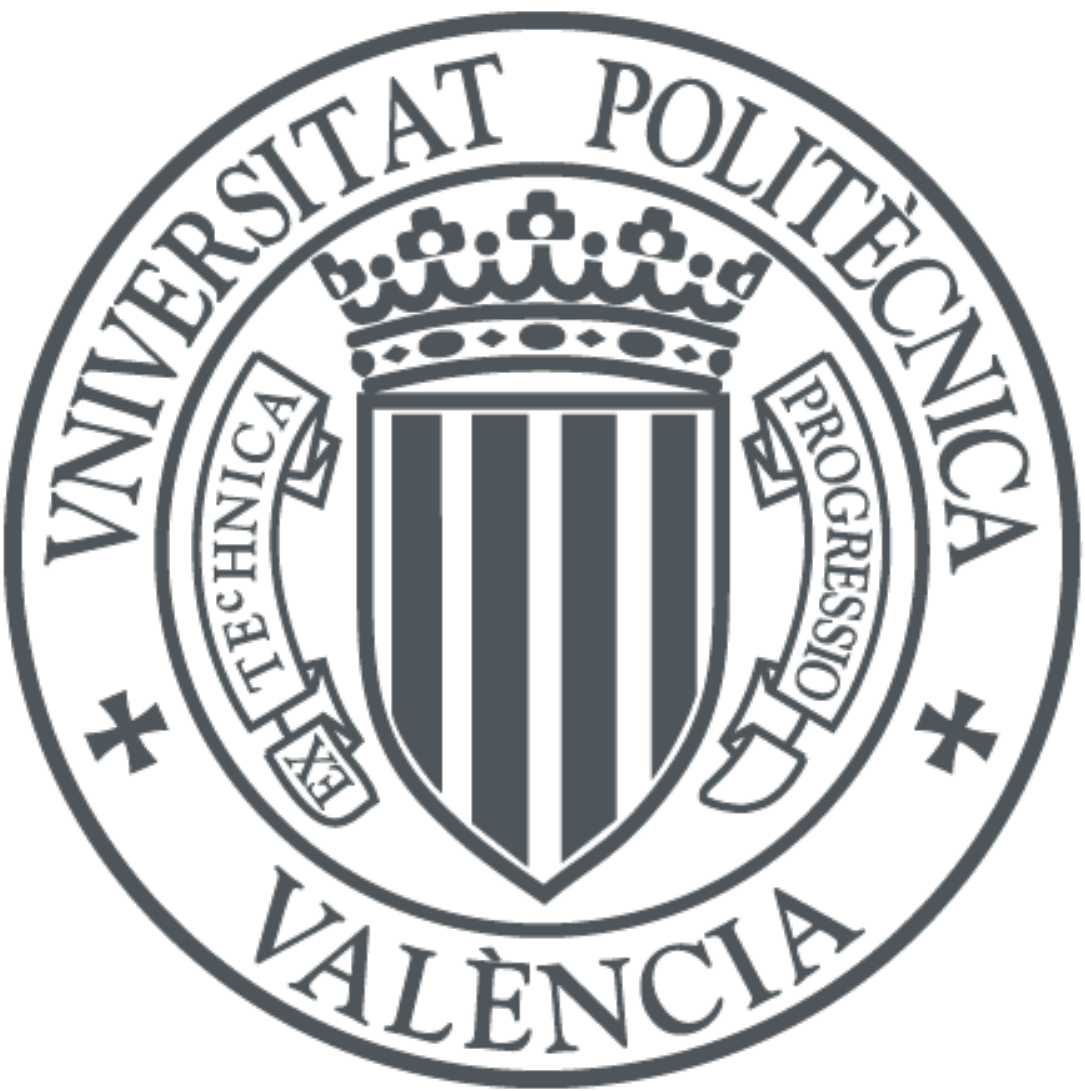

The final publication is available at

http://dx.doi.org/10.1016/j.biortech.2015.05.070

Copyright Elsevier

Additional Information 


\section{Effect of temperature on ammonium removal in Scenedesmus sp.}

Ruiz-Martínez, A.*,a , Serralta, J. ${ }^{\text {a }}$, Seco, A. ${ }^{\text {, }}$, and Ferrer, J. ${ }^{\text {a }}$

${ }^{a}$ Instituto de Ingeniería del Agua y Medio Ambiente, IIAMA, Universitat Politècnica de Valencia, Camino de Vera s/n, 46022 Valencia, Spain (e-mail: anruima1@upv.es, jserralt@hma.upv.es, jferrer@hma.upv.es)

bopartament d’Enginyeria Química, EscolaTècnica Superior d’Enginyeria, Universitat de València, Avinguda de la Universitat s/n. 46100 Burjassot, Valencia, Spain (email: aurora.seco@uv.es)

*Corresponding author. Tel. +34 963877000 ext. 76176; Fax +34 963877 618, e-mail address: anruima1@upv.es

\section{ABSTRACT}

The effect of temperature on microalgal ammonium uptake was investigated by carrying out four batch experiments in which a mixed culture of microalgae, composed mainly of Scenedesmus sp., was cultivated under different temperatures within the usual temperature working range in Mediterranean climate $\left(15-34^{\circ} \mathrm{C}\right)$. Ammonium removal rates increased with temperature up to $26^{\circ} \mathrm{C}$ and stabilized thereafter. Ratkowsky and Cardinal Temperatures models successfully reproduced the experimental data. Optimum $\left(31.3^{\circ} \mathrm{C}\right)$, minimum $\left(8.8^{\circ} \mathrm{C}\right)$ and maximum $\left(46.1^{\circ} \mathrm{C}\right)$ temperatures for ammonium removal by Scenedesmus sp. under the studied conditions were obtained as model parameters. These temperature-related parameters constitute very useful information for designing and operating wastewater treatment systems using these microalgae.

\section{Keywords}

Ammonium uptake; microalgae; modeling; temperature; wastewater. 


\section{HIGHLIGHTS}

Ratkowsky’s model accurately reproduced the temperature effect on ammonium removal

Cardinal temperatures model (CTM) obtained analogous results as Ratkowsky’s equation

The CTM is preferred due to the biological significance of its parameters

The obtained theoretical optimum temperature for ammonium removal was $31^{\circ} \mathrm{C}$

\section{INTRODUCTION}

Interest in microalgae has risen in the last decades due to the combination of several factors, three of which are highlighted here for their somewhat bigger impact on research: a) microalgae can be used to obtain renewable fuels such as biodiesel, biohydrogen or biogas, therefore contributing to reduce fossil fuel consumption b) microalgae use $\mathrm{CO}_{2}$ for their growth, and therefore contribute to reduce greenhouse gas emissions and c) pollutants such as phosphate, nitrate and ammonium can be successfully removed from wastewaters by microalgae, since they grow on inorganic nutrients which they take from the medium.

Several authors have indeed proved that the use of microalgae is a valid option for wastewater treatment, as reviewed by Wu et al. (2014). Many efforts have also been made to study their growth kinetics (Aslan and Kapdan 2006, Ruiz et al. 2013, Wu et al. 2013), or to predict their production of biomass or substances of interest, such as lipids or sugars (Adesanya et al. 2014, Tevatia et al. 2012). Temperature influence on microalgal growth has also been modeled in various ways. Béchet et al. (2013) and Ras et al. (2013) present reviews of this matter. The former recommends uncoupled models 
(those which do not account for interdependence of light and temperature) and the latter insists on the important effect that high temperatures and microalgal adaptation to environmental conditions have on the functioning of outdoor production systems.

Essentially, the Arrhenius Law (eq. 1) has been widely used for describing temperature influence on microalgal growth (for instance by Geider et al.1998 or Ketheesan and Nirmalakhandan 2013), although it was originally proposed for chemical reaction rates and it does not describe properly the negative effect of high temperature on microbial growth.

$\mu(T)=\mu\left(T_{r}\right) \cdot \theta^{\left(T-T_{r}\right)}$

where $T_{r}\left({ }^{\circ} \mathrm{C}\right)$ is the reference temperature and $\theta$ is the Arrhenius constant.

Ratkowsky et al. (1983) were the first to model the microbial growth rate reduction observed at temperatures above an optimum value (eq. 2).

$\sqrt{\mu(T)}=b \cdot\left(T-T_{\min }\right) \cdot\left\{1-\exp \left[c \cdot\left(T-T_{\max }\right)\right]\right\}$

where $\mathrm{b}$ and $\mathrm{c}$ are parameters with no biological meaning obtained by data fitting and $\mathrm{T}_{\min }$ and $\mathrm{T}_{\max }$ are the minimum and maximum temperatures, respectively, at which growth rate is zero.

Otherwise, Bernard and Rémond (2012) used the so-called cardinal temperature model with inflexion (CTMI) (eq. 3) to predict the effect of temperature on microalgal growth using parameters which all have a biological meaning:

$\mu=\mu_{\max } \cdot \frac{\left(T-T_{\max }\right) \cdot\left(T-T_{\min }\right)^{2}}{\left(T_{o p t}-T_{\min }\right) \cdot\left[\left(T_{o p t}-T_{\min }\right) \cdot\left(T-T_{o p t}\right)-\left(T_{o p t}-T_{\max }\right) \cdot\left(T_{o p t}+T_{\min }-2 T\right)\right]}$ 
Where $T_{\min }\left({ }^{\circ} \mathrm{C}\right)$ is the temperature below which the growth is assumed to be zero, $T_{\max }$ $\left({ }^{\circ} \mathrm{C}\right)$ is the temperature above which there is no growth and at temperature $\mathrm{T}_{\text {opt }}\left({ }^{\circ} \mathrm{C}\right)$ maximal growth rate $\mu_{\max }\left(\mathrm{d}^{-1}\right)$ occurs. To our knowledge, this expression has been previously used for microalgal growth only by this author.

The purpose of this study is to assess the direct influence of temperature on the ammonium uptake rate, due to the aforementioned interest on the microalgal ability to remove pollutants from wastewater, and to select a mathematical equation to model the observations. To this aim, four reactors seeded with a mixed culture of indigenous microalgae with clear predominance of Scenedesmus sp. were kept at different temperatures and the microalgal ammonium uptake rate was measured. The models previously detailed in this section were used to reproduce the observed data.

Temperature-related parameters for ammonium removal could thus be obtained.

\section{MATERIALS AND METHODS}

\subsection{Microorganisms}

Microalgae were isolated from the walls of the secondary clarifier in the WWTP “Cuenca del Carraixet” (Valencia, Spain) and maintained in the laboratory in a $7 \mathrm{l}$ semicontinuous reactor, using as growth medium the effluent of a pilot-scale submerged anaerobic membrane bioreactor (SAnMBR) which operates in the WWTP (Giménez et al. 2011). The SAnMBR treats a small fraction of the WWTP incoming wastewater, and therefore its effluent displays variable nutrient content of $30-50 \mathrm{mg} \mathrm{NH}-\mathrm{N} \cdot \mathrm{l}^{-1}$ and 4-7 $\mathrm{mg} \mathrm{PO} 4-\mathrm{P} \cdot \mathrm{l}^{-1}$. This effluent had previously proved to contain all necessary micronutrients to sustain algal growth (Ruiz-Martinez et al. 2012). The biomass formed a stable ecosystem where the dominant microalgae belonged to the Chloroccocal order, of which $>99 \%$ to the Scenedesmus genus. 


\subsection{Experimental setup and operation}

Four experiments were carried out in four cylindrical glass reactors with a total and working volume of 2 and $1.8 \mathrm{l}$, respectively. Around each reactor a coil of transparent silicon tube was installed for temperature control. Cooling/heating water temperatures were controlled by thermostatic baths (Lauda Alpha RA8). Reactors 1 to 4 were thus kept at $15{ }^{\circ} \mathrm{C}, 18{ }^{\circ} \mathrm{C}, 26^{\circ} \mathrm{C}$ and $34^{\circ} \mathrm{C}$, respectively. Each reactor was equipped with electronic sensors in order to obtain on-line temperature and $\mathrm{pH}$ measurements. The probes were connected to a multiparametric analyzer (CONSORT C832, Belgium), which was in turn connected to a PC for data monitoring and storage. Data sampling was conducted every $60 \mathrm{~s}$. A fine bubble diffuser was mounted at the bottom of each reactor in order to mix the algal culture by injecting compressed air. Pure (99.9\%) $\mathrm{CO}_{2}$ from a pressurized cylinder was injected into the compressed air flow whenever $\mathrm{pH}$ rose above 7.5. This $\mathrm{pH}$ control avoided phosphate precipitation and free ammonia stripping. The reactors stood in two confronted lines of two reactors each. From the front of the first line and from the back of the last line, a total of eight vertical fluorescent lamps (Sylvania Grolux, $18 \mathrm{~W}$ ) constantly illuminated the reactors (four lamps in the front and four lamps in the back). Photosynthetically active radiation (PAR) of $180 \pm 21 \mu \mathrm{E} \mathrm{m}^{-2} \mathrm{~s}^{-}$ ${ }^{1}$ was measured at the center of the empty setup.

At the beginning of the experiments, which were carried out in batch mode, $1300 \mathrm{ml}$ of the SAnMBR effluent (containing $34 \mathrm{mg} \mathrm{NH}-\mathrm{N} \cdot \mathrm{l}^{-1}$ and $5.6 \mathrm{mg} \mathrm{PO}_{4}-\mathrm{P} \cdot \mathrm{l}^{-1}$ ) were transferred into each reactor. Phosphate (in the form of $\mathrm{KH}_{2} \mathrm{PO}_{4}$ ) and ammonium (in the form of $\left.\left(\mathrm{NH}_{4}\right)_{2} \mathrm{SO}_{4}\right)$ were added to each reactor in order to reach the concentrations of $14 \mathrm{mg} \mathrm{PO}-\mathrm{P} \cdot \mathrm{l}^{-1}$ and $42 \mathrm{mg} \mathrm{NH}-\mathrm{N} \cdot \mathrm{l}^{-1}$, respectively. These values were considered high enough for avoiding $\mathrm{N}$ or $\mathrm{P}$ deficiency during the whole experiment. When the 
temperature setpoint was reached, $500 \mathrm{ml}$ of biomass culture (taken from the semicontinuous reactor as explained in section 2.1) were added to each reactor. Total Suspended Solids (TSS) measured in this culture allowed us to calculate the initial biomass concentration resulting in each reactor, which was $115 \mathrm{mg}$ TSS $\cdot \mathrm{l}^{-1}$. The experiments lasted between 25 and 53 hours, during which ammonium and biomass concentrations were measured periodically.

\subsection{Analytical Methods}

Ammonium and phosphate were determined according to Standard Methods (APHA 2005) (4500-NH3-G and 4500-P-F, respectively) in a Smartchem 200 automatic analyzer (Westco Scientific Instruments, Westco). TSS were determined at the beginning and the end of the experiment according to Standard Methods (APHA 2005), and calculated during the batch experiments using the equation which describes their linear relationship with absorbance. Absorbance was measured at $750 \mathrm{~nm}$ by a UV-VIS spectrophotometer (Merck Spectroquant ${ }^{\circledR}$ Pharo 300). All reported results were obtained from the previous analyses conducted in duplicate.

\section{RESULTS AND DISCUSSION}

\subsection{Temperature influence on ammonium uptake}

Initial ammonium concentration was measured in each reactor immediately after microalgae addition, and periodically during the rest of the experiment. Time evolution of ammonium concentrations in the four reactors is shown in figure 1. It is hypothesized that initial ammonium concentrations are not identical in all experiments due to the time lapse (for temperature stabilization) between nutrient addition in the reactors and microalgae addition (when the $\mathrm{pH}$ control system was switched on). Ammonium concentrations always decreased at a constant rate in all the reactors: four straight lines 
can be observed in figure 1 , one for each temperature tested. The slope of each line represents the ammonium removal rate of the corresponding reactor. The least-squares fitting method from Excel ${ }^{\circledR}$ was applied to fit the obtained data and to calculate the slope of each trendline.

$$
\begin{array}{ll}
\mathrm{r}_{\mathrm{NH} 4-15^{\circ} \mathrm{C}}=4.3 \mathrm{mg} \mathrm{N} \cdot \mathrm{l}^{-1} \cdot \mathrm{d}^{-1} & \mathrm{r}_{\mathrm{NH} 4-18^{\circ} \mathrm{C}}=6.7 \mathrm{mg} \mathrm{N} \cdot \mathrm{l}^{-1} \cdot \mathrm{d}^{-1} \\
\mathrm{r}_{\mathrm{NH} 4-26^{\circ} \mathrm{C}}=15.7 \mathrm{mg} \mathrm{N} \cdot \mathrm{l}^{-1} \cdot \mathrm{d}^{-1} & \mathrm{r}_{\mathrm{NH} 4-34^{\circ} \mathrm{C}}=17 \mathrm{mg} \mathrm{N} \cdot \mathrm{l}^{-1} \cdot \mathrm{d}^{-1}
\end{array}
$$

These values are in the same range or higher than those obtained by other authors. Park and Jin. (2010) reported an ammonium removal rate of 5-6 $\mathrm{mg} \mathrm{N} \cdot \mathrm{l}^{-1} \cdot \mathrm{d}^{-1}$ by Scenedesmus sp. from a piggery farm wastewater with no mention to temperature. Voltolina et al. (2005) reported an ammonium removal rate of $8-9 \mathrm{mg} \mathrm{N} \cdot \mathrm{l}^{-1} \cdot \mathrm{d}^{-1}$ by Scenedesmus obliquus in artificial wastewater at $25.5^{\circ} \mathrm{C}$, which is a smaller value than the one obtained in this study for a similar temperature. Also at $25^{\circ} \mathrm{C}$, Kim et al. (2013) optimized nitrogen removal by Scenedesmus sp. by changing the wavelength of the used light, and reported a maximum removal rate of $15 \mathrm{mg} \mathrm{N} \cdot \mathrm{l}^{-1} \cdot \mathrm{d}^{-1}$, which is similar to the value obtained in this study.

Phosphate concentrations in the reactors were measured at the end of each experiment to rule out any possible effect of phosphorus limitation. Phosphorus limitation was discarded since phosphate levels in the reactors remained in all cases above $5 \mathrm{mg} \mathrm{PO}_{4}$ $\mathrm{P} \cdot \mathrm{l}^{-1}$.

Regarding the variation of ammonium removal rates with temperature, a bell-shaped curved is expected for describing the relationship between microalgal activity and temperature, although individual shapes are species dependent, and also influenced by environmental conditions (Ras et al. 2013). In this study, a fast (lineal) increase was 
observed for the first three temperatures evaluated: ammonium removal rate at $26{ }^{\circ} \mathrm{C}$ was twice the value obtained at $18^{\circ}$. In contrast, no substantial difference was observed between the values obtained at $26^{\circ} \mathrm{C}$ and at $34^{\circ} \mathrm{C}$.

It is undeniable that temperature is an operation parameter which, being on the one hand relatively easy to control, defines on the other hand the refrigerating or heating costs of the process, which might amount to a high fraction of the total costs and affect process sustainability. Taking the influence of temperature on ammonium removal rate into account can help optimizing the compromise between operation costs and removal efficiency.

\subsection{Mathematical models evaluation and calibration}

Using the Solver program in Microsoft ${ }^{\circledR}$ Excel 2007 software for minimizing the residual sum of squared errors between the experimental data and the model predictions, experimental data were accurately reproduced with Ratkowsky’s expression (figure 2a), obtaining the following parameter values:

$\mathrm{b}=0.36 \quad \mathrm{c}=0.04 \quad \mathrm{~T}_{\min }=7.1^{\circ} \mathrm{C} \quad \mathrm{T}_{\max }=47.4^{\circ} \mathrm{C}$

Statistical analysis was carried out using SPSS 16.1. Pearson correlation coefficient (Pvalue $<0.01$ ) was 0.998 .

The cardinal temperature model with inflexion (CTMI) adopted by Bernard and Rémond (2012) for microalgal growth could also accurately reproduce the experimental data of ammonium removal rates (figure 2b). Pearson coefficient (P-value $<0.01$ ) was 0.997 and the following parameter values were obtained:

$$
\mathrm{r}_{\mathrm{NH} 4 \max }=17.5 \mathrm{mg} \mathrm{N} \cdot \mathrm{l}^{-1} \cdot \mathrm{d}^{-1} \quad \mathrm{~T}_{\min }=8.8^{\circ} \mathrm{C} \quad \mathrm{T}_{\max }=46.1^{\circ} \mathrm{C} \quad \mathrm{T}_{\mathrm{opt}}=31.3^{\circ} \mathrm{C}
$$


Maximum ammonium removal rate obtained is in agreement with our observations. Minimum and maximum temperatures are in accordance with the values obtained with Ratkowsky’s model, as well as optimum temperature. Although Ratkowsky’s model does not include a model parameter representing the optimum temperature as such, it does predict an optimum temperature around $30{ }^{\circ} \mathrm{C}$ (see figure $2 \mathrm{a}$ ).

The shape of the removal rate curve versus temperature is in the case of the CTMI more asymmetrical, showing a faster decrease after the optimum temperature. The area under the curve is also smaller, since the minimum temperature is slightly higher than in the case of the Ratkowsky's equation, and the maximum temperature is slightly smaller. Nonetheless, the predictions obtained with both models are very similar, and both models accurately reproduced the experimental data. Under these circumstances, the CTMI expression was preferred for modeling the effect of the temperature on the ammonium removal rate of Scenedesmus sp. under the studied conditions, since the parameters have a biological significance whose meaning is straightforward to understand, thus making calibration easier (for instance the decision for the initial values of parameters). In contrast, parameters b and c in Ratkowsky's model have no direct biological interpretation, being mathematical parameters defined in order to reproduce the experimental data.

Hodaifa (2010) reported an optimum temperature for Scenedesmus obliquus growth rate of $29.6{ }^{\circ} \mathrm{C}$, and Sanchez (2008) reported, for Scenedesmus almeriensis, optimum growth temperatures of $30-35^{\circ} \mathrm{C}$ depending on light intensity and a maximum temperature of $48{ }^{\circ} \mathrm{C}$. These parameters are in agreement with the ones obtained in this study. 


\section{CONCLUSIONS}

This work describes the effect of temperature on ammonium removal rate of the microalgae Scenedesmus sp. The cardinal temperature model used by Bernard and Rédmond (2012) for microalgal growth was successfully used to fit the data and to obtain theoretical minimum, maximum and optimum temperatures for ammonium removal by Scenedesmus sp. This information is very useful for the operation of microalgae based wastewater treatment systems, since removal rates are affected by temperature, which is an easy to control parameter while at the same time responsible for a percentage of the operation costs.

\section{ACKNOWLEDGEMENTS}

This work has been supported by the Spanish Ministry of Economy and Competitiveness (MINECO, CTM2011-28595-C02-01/02), the European Regional Development Fund (ERDF) and the Spanish Ministry of Science and Innovation (pre doctoral FPU fellowship to the first author (AP2009-4903)). The support is gratefully acknowledged. The authors would also like to thank the water management entities of the Generalitat Valenciana (EPSAR).

\section{REFERENCES}

1. Adesanya, V.O., Davey, M.P., Scott, S.S., Smith, A.G. (2014) Kinetic modelling of growth and storage molecule production in microalgae under mixotrophic and autotrophic conditions. Bioresour Technol 157, 293-304.

2. APHA (2005) Standard methods for the examination of water and wastewater, 20th ed., American Public Health Association, Washington, DC. 
3. Aslan, S., Kapdan, I.K. (2006) Batch kinetics of nitrogen and phosphorus removal from synthetic wastewater by algae. Ecol Eng 28, 64-70.

4. Béchet, Q., Shilton, A., Guieysse, B. (2013) Modeling the effects of light and temperature on algae growth: State of the arte and critical assessment for productivity prediction during outdoor cultivation. Biotechnol Adv 31, 16481663.

5. Bernard, O., Rémond, B. (2012) Validation of a simple model accounting for light and temperature effect on microalgal growth. Bioresour Technol 123, 520527.

6. Geider, R.J., MacIntyre, H.L., Kana, T.M. (1998) A dynamic regulatory model of phytoplanktonic acclimation to light, nutrients, and temperature. Limnol Oceanogr 43, 679-694.

7. Giménez, J.B., Robles, A., Carretero, L., Duran, F., Ruano, M.V., Gatti, M.N., Ribes, J., Ferrer, J., Seco, A. (2011) Experimental study of the anaerobic urban wastewater treatment in a submerged hollow-fibre membrane bioreactor at pilot scale. Bioresour Technol 102, 8799-8806.

8. Hodaifa, G., Martínez, M.E., Sánchez. S. (2010) Influence of temperature on growth of Scenedesmus obliquus in diluted olive mill wastewater as culture medium. Eng Life Sci 10 (3), 257-264.

9. Ketheesan, B., Nirmalakhandan, N. (2013) Modeling microalgal growth in an airlift-driven raceway reactor. Bioresour Technol 136, 689-696.

10. Kim, T-H, Lee, Y., Han, S-H, Hwang, S-J (2013) The effects of wavelength and wavelength mixing ratios on microalgae growth and nitrogen, phosphorus 
removal using Scenedesmus sp. for wastewater treatment. Bioresour Technol 130, $75-80$.

11. Park, J., Jin, H. (2010) Ammonia removal from anaerobic digestion effluent of livestock waste using green alga Scenedesmus sp. Bioresour Technol 101, 86498657.

12. Ras, M., Steyer, J-P., Bernard, O. (2013) Temperature effect of microalgae: a crucial factor for outdoor production. Rev Environ Sci Biotechnol 12 (2), 153164.

13. Ratkowsky, D.A., Lowry, R.K., McMeekin, T.A., Stokes, A.N., Chandler, R.E. (1983) Model for bacterial culture growth rate throughout the entire biokinetic temperature range. J Bacteriol 154, 1222-1226.

14. Ruiz, J., Arbib, Z., Álvarez-Diaz, P.D., Garrido-Pérez, C., Barragán, J., Perales, J.A. (2013) Photobiotreatment model (PhBT): a kinetic model for microalgae biomass growth and nutrient removal in wastewater. Environ Technol 34 (8), 979-991.

15. Ruiz-Martinez, A., Martin Garcia, N., Romero, I., Seco, A., Ferrer, J. (2012) Microalgae cultivation in wastewater: Nutrient removal from anaerobic membrane bioreactor effluent. Bioresour Technol 126, 247-253.

16. Sánchez, J.F., Fernández-Sevilla, J.M., Acién, F.G., Cerón, M.C., Pérez-Parra, J., Molina-Grima, E. (2008) Biomass and lutein productivity of Scenedesmus almeriensis: influence of irradiance, dilution rate and temperature. Appl Microbiol Biotechnol 79, 719-729. 
17. Tevatia, R., Demirel, Y., Blum, P. (2012) Kinetic Modeling of Photoautotropic Growth and Neutral Lipid Accumulation in terms of Ammonium Concentration in Chlamydomonas reinhardtii. Bioresour Technol 119, 419-424.

18. Voltolina, D., Gómez-Villa, H., Correa, G. (2005) Nitrogen removal and recycling by Scenedesmus obliquus in semicontinuous cultures using artificial wastewater and a simulated light and temperature cycle. Bioresour Technol 96, 359-362.

19. Wu, Y.H., Li, X., Yu, Y., Hu, H.Y., Zhang, T.Y., Li, F.M. (2013) An integrated microalgal growth model and its application to optimize the biomass production of Scenedesmus sp. LX1 in open pond under the nutrient level of domestic secondary effluent. Bioresour Technol 144, 445-451.

20. Wu, Y-H., Hu, H-Y., Yu, Y., Zhang, T-Y, Zhu, S-F, Zhuang, L-L, Zhang, X., Lu, Y. (2014) Microalgal species for sustainable biomass/lipid production using wastewater as resource: A review. Renew Sust Energ Rev 33, 675-688.

\section{FIGURE CAPTIONS}

Figure 1: Experimental data: Ammonium concentrations measured in each reactor during the experiment.

Figure 2: Data fitted using a) Ratkowsky’s equation and b) the cardinal temperature model with inflexion 